\title{
Preparation of Soluble Poly(iminoarylene)s by Palladium-Catalyzed Polycondensation of Aryl Dibromides with Aryl Primary Diamines
}

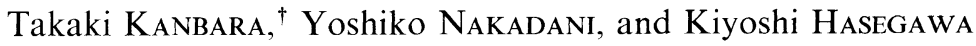 \\ Department of Chemical and Biochemical Engineering, Faculty of Engineering, Toyama University, \\ 3190 Gofuku, Toyama 930-8555, Japan
}

(Received September 3, 1998)

KEY WORDS Polycondensation / Palladium complex / Poly(iminoarylene) /

Numerous reports have been published on palladium (Pd) complex catalyzed polycondensation to give poly(arylene)s, polyesters, polyamides, and related polymers. ${ }^{1}$ Recently, catalytic amination reactions of aryl halides with amines using Pd complexes have been investigated, ${ }^{2}$ and preparation of poly(arylenediamine)s by the Pd-catalyzed polycondensation of aryl dibromides with diamines has also been reported. ${ }^{3}$ In the course of the investigation, Meyer et al. and we have carried out the Pd-catalyzed polycondensation of 1,3-dibromobenzene with 1,3-phenylenediamine to give poly(imino-1,3phenylene) in a good yield, and the obtained polymer showed good solubility in polar solvents. ${ }^{3 \mathrm{~b}, \mathrm{e}}$

Poly(imino-1,3-phenylene) and some of the related poly(iminoarylene)s have been prepared by the Ullmann polycondensation, ${ }^{4}$ and the polymers exhibited ferromagnetic interaction after oxidation. However, the obtained polymers showed low solubility, presumably due to potential cross-linking and possible regioirregularity, ${ }^{4 d, f . g}$ which prevented full characterization of the polymers. Preparation of regioregular poly(iminoarylene)s would be crucial for the study on the correlation of magnetic properties with the polymer structure.

These informations prompted us to examine the Pdcatalyzed polycondensation of various aryl dibromides with aryl primary diamines to afford a variety of homo and/or alternating poly(iminoarylene)s.

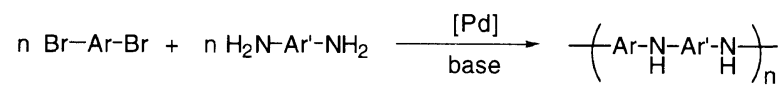

The Pd-catalyzed polycondensation proceeds under mild conditions and is expected to minimize the potential for cross-linking and to preclude regioirregularities. We here report the results of preparation of various soluble poly(iminoarylene)s by the $\mathrm{Pd}$-catalyzed polycondensation.

\section{EXPERIMENTAL}

IR and NMR spectra were recorded on a JASCO FT/IR-230 spectrometer and JEOL JNM-A400 NMR spectrometer, respectively. GPC analyses were performed with a JASCO 880 system using a Tosoh TSK-Gel G4000 HHR column using an $N, N$-dimethylformamide (DMF) solution of $\mathrm{LiCl}(0.01 \mathrm{M})$ as an eluent (polystyrene

$\dagger$ To whom correspondence should be addressed. standards). Elemental analyses were carried out with a Yanaco CHN Corder MT-5 and a Yanaco SX-Elements Micro analyzer.

The Pd-catalyzed polycondensation of aryl dibromides with aryl diamines was carried out under $\mathrm{N}_{2}$ in a manner analogous to that previously reported. ${ }^{3 \mathrm{~b}}$ A mixture of aryl dibromide $(2 \mathrm{mmol})$ and aryl primary diamine $(2 \mathrm{mmol})$ was dissolved in toluene $(15 \mathrm{ml})$. Sodium- $t$ butoxide (NaO- $t$-Bu) $(577 \mathrm{mg}, 6 \mathrm{mmol})$, tris(dibenzylideneacetone)-dipalladium $\left(\mathrm{Pd}_{2}(\mathrm{dba})_{3}\right)(46 \mathrm{mg}, 0.05 \mathrm{mmol})$, and 2,2'-bis(diphenylphosphino)-1,1'-binaphthyl (BINAP) $(93 \mathrm{mg}, 0.15 \mathrm{mmol})$ were added to the solution at room temperature. The reaction mixture was stirred at $100^{\circ} \mathrm{C}$ for $16 \mathrm{~h}$ under $\mathrm{N}_{2}$. After cooling to room temperature, the mixture was poured into a mixture of aqueous ammonia and methanol $(200 \mathrm{ml}, 1 / 4, \mathrm{v} / \mathrm{v})$, and the precipitate was separated by filtration. The precipitate was washed thoroughly with aqueous ammonia and methanol.

\section{RESULTS AND DISCUSSION}

In our previous study, the combination of $\mathrm{Pd}_{2}(\mathrm{dba})_{3}$ and BINAP has been found to be the most effective catalyst system for preparation of poly(imino-1,3-phenylene). ${ }^{3 b}$ Table I summarizes the results of the Pd-catalyzed polycondensation of several aryl dibromides with aryl primary diamines using the catalyst system. The reactions of 1,3-dibromobenzene with aryl diamines having electron-donating substituents (Runs 2-4) as well as electron-withdrawing substituents (Runs 5,6) provided the corresponding poly(iminoarylene)s in good yields. The Pd-catalyzed aryl amination involves $\beta$-hydrogen elimination reaction of the Pd-intermediate. ${ }^{2 \mathrm{a}-\mathrm{e}}$ Use of the aryl diamines as monomer depressed the undesired side reaction and achieved high yields. The molecular weights of the polymers were calibrated by GPC. ${ }^{5}$ The obtained polymers have large polydispersity, which would be due to low solubility of the polymers in toluene and formation of the precipitate during the polymerization.

Pyridine has been found to inhibit the Pd-catalyzed amination of aryl bromides due to displacement of phosphine ligands from the catalytic intermediates to form bis(pyridine) complexes. ${ }^{2 \mathrm{f}}$ Buchwald et al. have reported that the Pd-complexes with chelating bis(phosphine) ligands such as BINAP suppress the ligand exchange and effectively catalyze the amination of halo- 
Table I. Pd-catalyzed polycondensation of aryl dibromides with aryl primary diamines ${ }^{a}$

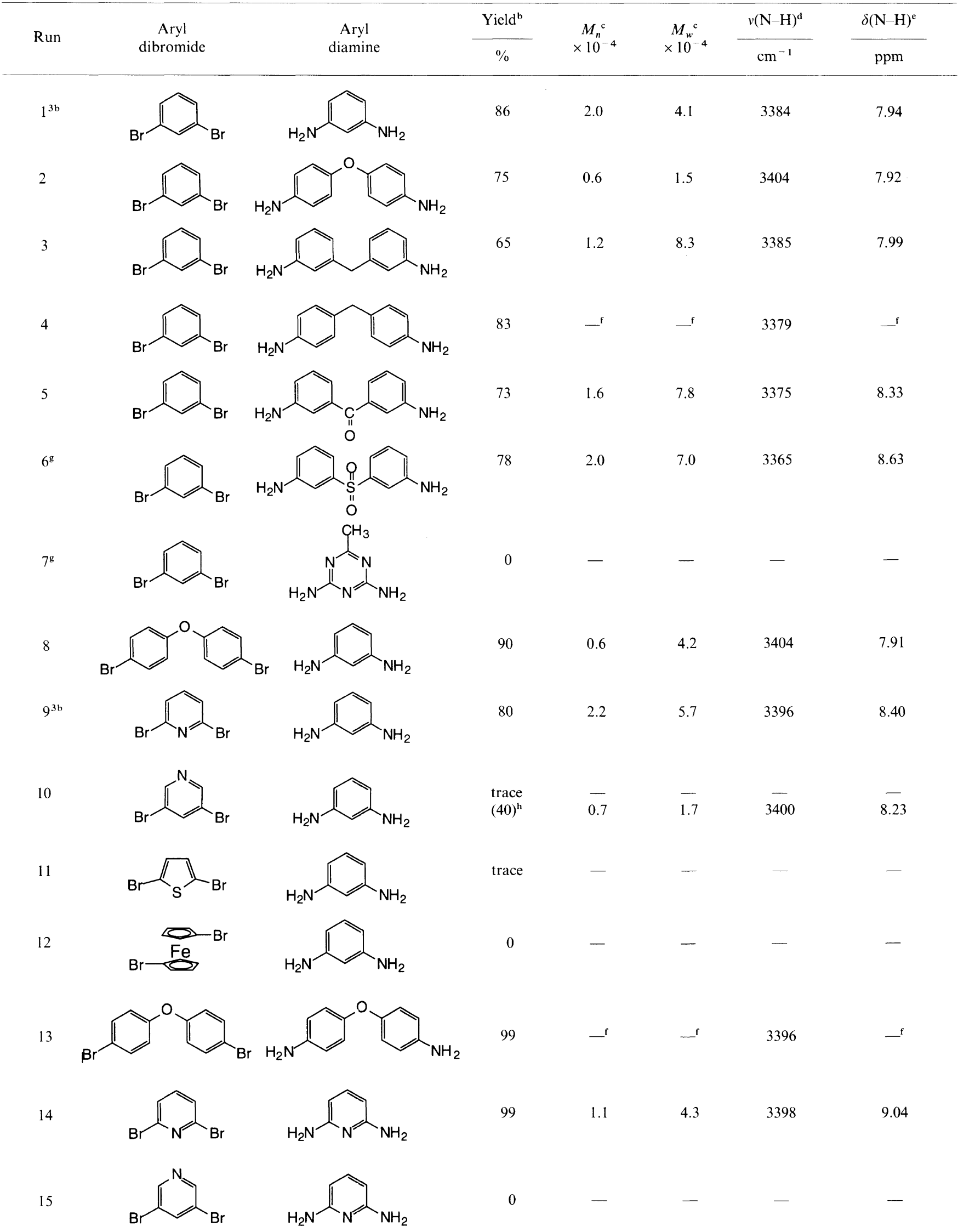

${ }^{a}$ Polycondensation was carried out in the presence of $\mathrm{NaO}-t$-Bu (3 equiv. for monomer), $\mathrm{Pd}_{2}(\mathrm{dba})_{3}(2.5 \mathrm{~mol} \%$ for monomer), and $\mathrm{BINAP}$ ( $7.5 \mathrm{~mol} \%$ for monomer) in toluene at $100^{\circ} \mathrm{C}$ for $16 \mathrm{~h}$ under $\mathrm{N}_{2}$. ${ }^{\mathrm{b}}$ Insoluble fraction in methanol. ${ }^{\mathrm{c}} \mathrm{Calibrated} \mathrm{by} \mathrm{GPC}$ with polystyrene standards. ${ }^{\mathrm{d}}$ Infrared band attributable to $v(\mathrm{~N}-\mathrm{H})\left(\mathrm{KBr}\right.$ pellet). ${ }^{\mathrm{e} 1} \mathrm{H}$ NMR chemical shift assignable to N-H (in DMSO- $d_{6}$ ). ${ }^{\mathrm{f}} \mathrm{Not}$ measured due to low solubility in organic solvents. ${ }^{\mathrm{g}}$ Reaction was run in dioxane instead of toluene due to the low solubility of monomer in toluene. ${ }^{\mathrm{h}}$ Reaction was run with $\mathrm{P}(t \text {-butyl })_{3}(15 \mathrm{~mol} \%$ for monomer $)$ instead of BINAP. 
T. Kanbara, Y. NaKadani, and K. HaSegawa
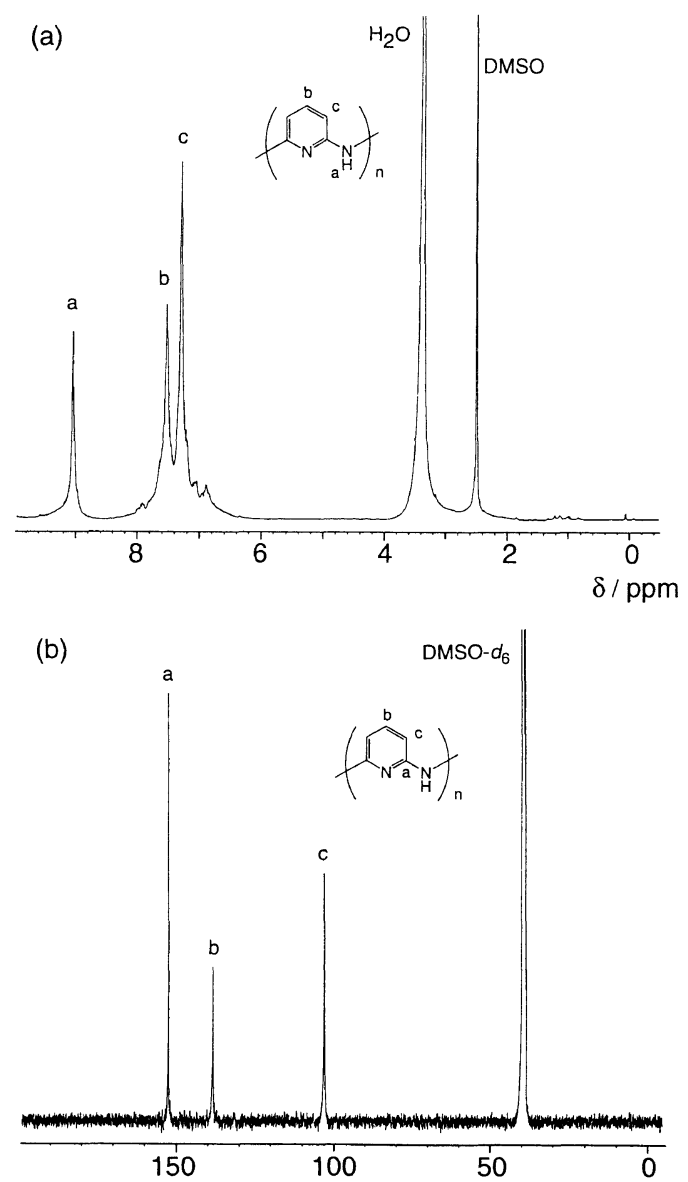

Figure 1. ${ }^{1} \mathrm{H}$ (a) and ${ }^{13} \mathrm{C}$ (b) NMR spectra of poly(2,6-pyridinediylimine) (Table I, Run 14) in DMSO- $d_{6}$.

pyridines. Actually, the polycondensation using 2,6dibromopyridine and/or 2,6-diaminopyridine afforded the corresponding poly(iminoarylene)s in good yields (Runs 9, 14). However, the catalyst system was not general. The reaction using neither 3,5-dibromopyridine nor 2,6-diamino-4-methyl-1,3,5-triazine resulted in product formation (Runs 7, 10, 15). Use of tri( $t$-butyl)phosphine $\left(\mathrm{P}(t \text {-butyl })_{3}\right)$ instead of BINAP (Run 10) afforded the polymer in a low yield. Use of electronrich heteroaromatic dibromides such as 2,5-dibromo thiophene and $1,1^{\prime}$-dibromoferrocene also failed to form product.

Elemental analysis data of the polymers are reasonable for the calculated values for the corresponding structures. ${ }^{6}$ The structures of the polymers were confirmed by IR and NMR spectroscopy. IR spectra of the polymers exhibit a peak assigned as $v(\mathrm{~N}-\mathrm{H})$ (Table I), and no absorbance for aromatic bromides was observed. Other IR spectroscopic data also support the proposed structures of the polymers.

The obtained polymers, except two samples (Runs 4, 13), are soluble in polar solvents such as DMF, $\mathrm{N}, \mathrm{N}$-dimethylacetamide, dimethylsulfoxide (DMSO), and 1-methyl-2-pyrrolidinone, and in acidic solvents such as formic acid and trifluoroacetic acid. Figures 1 and 2 show ${ }^{1} \mathrm{H}$ and ${ }^{13} \mathrm{C}$ NMR spectra of poly(2,6-pyridinediylimine) and poly(sulfonyl-1,3-phenyleneimino-1,3phenyleneimino-1,3-phenylene) (Runs 14,6) in DMSO$d_{6}$, respectively. Assignment of the peaks was carried out by comparison of the peak positions of the poly-
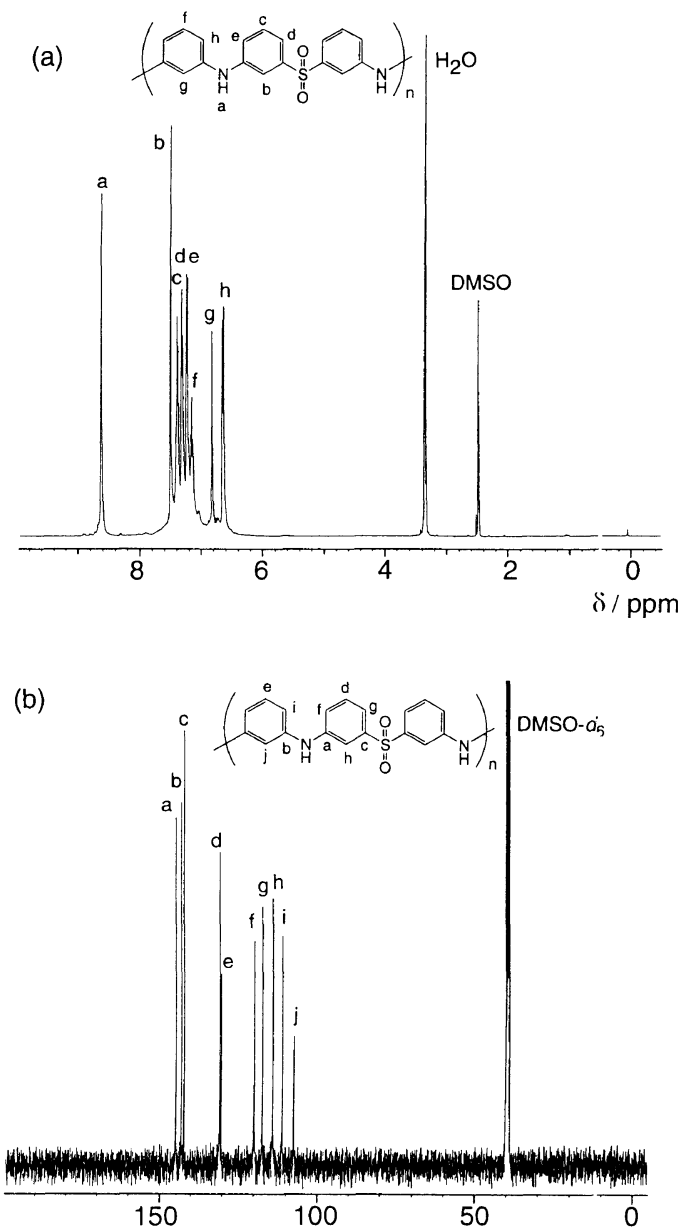

Figure 2. ${ }^{1} \mathrm{H}$ (a) and ${ }^{13} \mathrm{C}$ (b) NMR spectra of poly(sulfonyl-1,3phenyleneimino-1,3-phenyleneimino-1,3-phenylene) (Table I, Run 6) in DMSO- $d_{6}$.

mers with those of the monomers. In the ${ }^{1} \mathrm{H}$ NMR spectra, the peaks assignable to the primary amino groups ( $\delta 5.3$ for 2,6-diaminopyridine and $\delta 5.7 \mathrm{ppm}$ for 3,3'-diaminodiphenylsulfone) were scarcely observed, and a peak assignable to the secondary $\mathrm{N}-\mathrm{H}$ group (Table I) was confirmed by decrease upon addition of $\mathrm{D}_{2} \mathrm{O}$. The ratios of the peak area agree with the suggested assignment. The ${ }^{13} \mathrm{C}$ NMR spectra were also confirmed by DEPT spectra. NMR data of other polymers are also reasonable for their structures.

Marder et al. and Senanayake et al. have recently reported the $\mathrm{Pd}$-catalyzed selective aryl amination by primary amines in the presence of secondary amines. ${ }^{2 \mathrm{~h}, 1}$ Meyer et al. have demonstrated a model study for preparation of poly(imino-1,3-phenylene) to be primarily linear. ${ }^{3 \mathrm{e}}$ These observations as well as our spectroscopic results described above indicate that the Pd-catalyzed polycondensation affords no or scarcely cross-linked poly(iminoarylene)s with a well-defined structure. Since the polycondensation provides a variety of soluble poly(iminoarylene)s constituted of same and/or alternating aromatic units by changing the structure of aryl dibromides and/or aryl diamines, this procedure could extend molecular design and applications of polyarylamines.

Acknowledgment. The authors are grateful for the financial support by a Grant-in-Aid for Scientific Re- 
search (No. 09750972) from the Ministry of Education, Science, Sports and Culture of Japan.

\section{REFERENCES AND NOTES}

1. A.-D. Schlüter and G. Wegner, Acta Polym., 44, 59 (1993); W. Heitz, Angew. Makromol. Chem., 223, 135 (1994); M. Suzuki, J. Synth. Org. Chem.Jpn., 51, 141 (1993); Y. Imai and M. Yoneyama, ibid., 51, 794 (1993); T. Yamamoto, ibid., 53, 999 (1995); Prog. Polym. Sci., 17, 1153 (1992).

2. (a) J. F. Hartwig, Synlett, 329 (1997); (b) A. S. Guram, R. A Rennels, and S. L. Buchwald, Angew. Chem. Int. Ed. Engl., 34, 1348 (1995); (c) J. F. Hartwig, S. Richards, D. Barañano, and F. Paul, J. Am. Chem. Soc., 118, 3626 (1996); (d) J. P. Wolfe, S. Wagaw, and S. L. Buchwald, ibid., 118, 7215 (1996); (e) M. S. Driver and J. F. Hartwig, ibid., 119, 8232 (1997); (f) S. Wagaw and S. L. Buchwald, J. Org. Chem., 61, 7240 (1996); (g) J. P. Wolfe and S. L. Buchwald, ibid., 62, 1264 (1997); (h) S. Thayumanavan, S. Barlow, and S. R. Marder, Chem. Mater., 9, 3231 (1997); (i) N. P. Reddy and M. Tanaka, Tetrahedron Lett. 38, 4807 (1997); (j) M. Nishiyama, T. Yamamoto, and Y. Koie, ibid., 39, 617 (1998); (k) T. Yamamoto, M. Nishiyama, and Y. Koie, ibid., 39, 2367 (1998); (l) Y. Hong, C. H. Senanayake, T. Xiang, C. P. Vandenbossche, G. J. Tanoury, R. P. Bakale, and S. A. Wald, ibid., 39, 3121 (1998); (m) B. Witulski, S. Senft, and A. Thum, Synlett, 504 (1998).
3. (a) T. Kanbara, A. Honma, and K. Hasegawa, Chem. Lett., 1135 (1996); (b) T. Kanbara, K. Izumi, Y. Nakadani, T. Narise, and K. Hasegawa, ibid., 1185 (1997); (c) T. Kanbara, K. Izumi, T. Narise, and K. Hasegawa, Polym. J., 30, 66 (1998); (d) F. E. Goodson and J. F. Hartwig, Macromolecules, 31, 1700 (1998); (e) N. Spetseris, R. E. Ward, and T. Y. Meyer, ibid., 31, 3158 (1998).

4. (a) K. Yoshizawa, K. Tanaka, and T. Yamabe, Chem. Lett., 1311 (1990); (b) T. Ishida and H. Iwamura, ibid., 317 (1991); (c) K. Tanaka, K. Yoshizawa, A. Tanaka, T. Yamabe, and J. Yamauchi, Synth. Met., 41-43, 3297 (1991); (d) K. Yoshizawa, A. Ito, K. Tanaka, and T. Yamabe, ibid., 48, 271 (1992); (e) K. Yoshizawa, K. Tanaka, T. Yamabe, and J. Yamauchi, J. Chem. Phys., 96, 5516 (1992); (f) A. Ito, K. Ota, K. Tanaka, T. Yamabe, and K. Yoshizawa, Macromolecules, 28, 5618 (1995); (g) H. Goto, K. Iino, K. Akagi, and H. Shirakawa, Synth. Met., 85, 1683 (1997).

5. Since GPC is a measure of the hydrodynamic volume and not the molecular weight, considerable yet consistent error in $M_{n}$ and $M_{w}$ would usually result when comparing the rigid helical polymers to the flexible coil of polystyrene standards.

6. Run 1 in Table I: Anal. Calcd for $\left(\mathrm{C}_{6} \mathrm{H}_{5} \mathrm{~N}\right)_{n}: \mathrm{C}, 79.1 \% ; \mathrm{H}, 5.5 \%$; $\mathrm{N}, 15.4 \%$. Found: C, $78.8 \% ; \mathrm{H}, 5.6 \% ; \mathrm{N}, 14.4 \% ; \mathrm{Br}, 0.0 \%$. Run 6 in Table I: Anal. Calcd for $\left(\mathrm{C}_{18} \mathrm{H}_{14} \mathrm{~N}_{2} \mathrm{O}_{2} \mathrm{~S}\right)_{n}$ : C, $67.1 \% ; \mathrm{H}$, $4.4 \%$; N, $8.7 \%$. Found: C, $66.4 \% ; \mathrm{H}, 4.5 \% ; \mathrm{N}, 8.4 \% ; \mathrm{Br}, 0.3 \%$ Run 14 in Table I: Anal. Calcd for $\left(\mathrm{C}_{5} \mathrm{H}_{4} \mathrm{~N}_{2}\right)_{n}$ : C, $65.2 \% ; \mathrm{H}$, $4.4 \% ; \mathrm{N}, 30.4 \%$. Found: C, $64.6 \% ; \mathrm{H}, 4.3 \% ; \mathrm{N}, 28.5 \% ; \mathrm{Br}, 0.4 \%$. 